UCRL-JC-122125

CONF-9605 $40-2$

\title{
Preliminary Results of the LLNL Airborne Experimental Test-Bed SAR System
}

\author{
RECEIVED
}

FEB 061996

\author{
M. G. Miller, C. J. Mullenhoff, R. D. Kiefer, O S.T I
J. M. Brase, M. G. Wieting, G. L. Berry, \\ and $\mathrm{H}$. E. Jones
}

This paper was prepared for submittal to the

IEEE 1996 National Radar Conference

Ann Arbor, MI

May 13-16, 1996

January 16, 1996

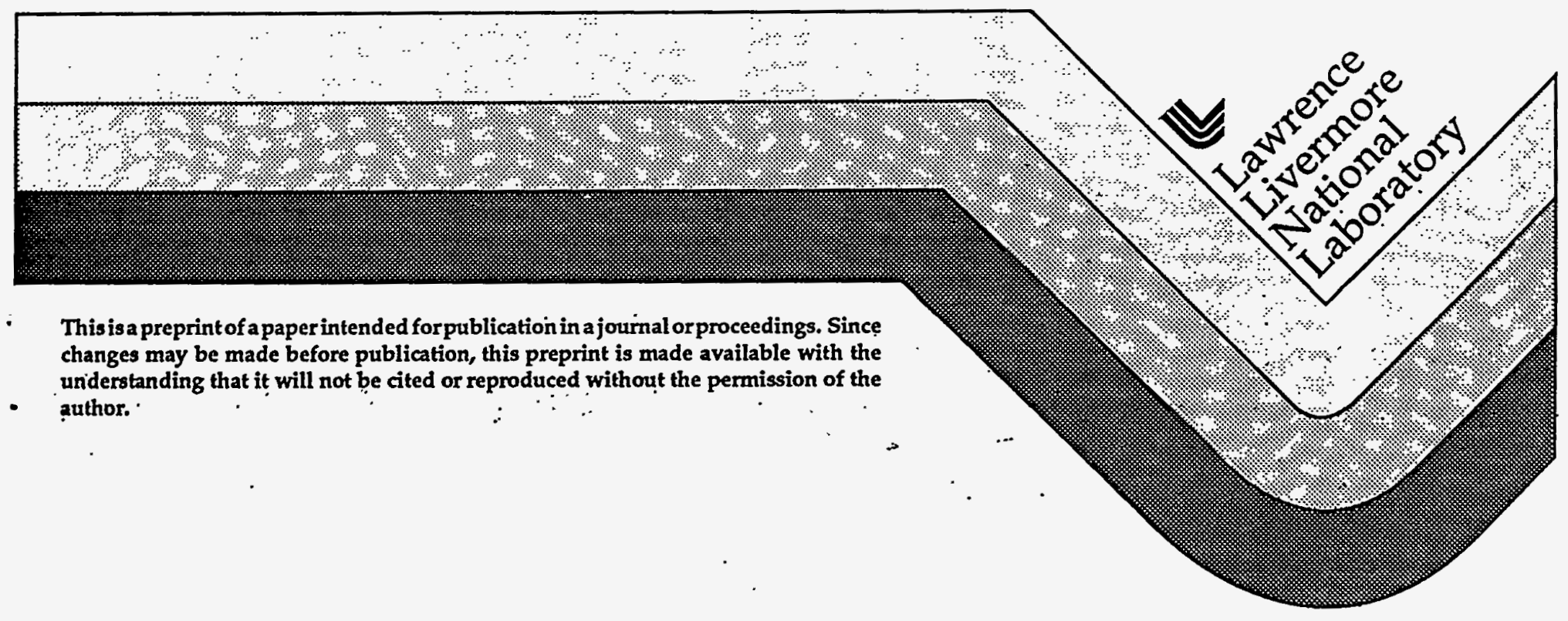

This is a preprint of a paperintended for publication in a journal or proceedings. Since changes may be made before publication, this preprint is made available with the uniderstanding that it will not be cited or reproduced without the permission of the author. 
This document was prepared as an account of work sponsored by an agency of the United States Government. Neither the United States Government nor the University of California nor any of their employees, makes any warranty, express or implied, or assumes any legal liability or responsibility for the accuracy, completeness, or usefulness of any information, apparatus, product, or process disclosed, or represents that its use would not infringe privately owned rights. Reference herein to any specific commercial product, process, or service by trade name, trademark, manufacturer, or otherwise, does not necessarily constitute or imply its endorsement, recommendation, or favoring by the United States Government or the University of California. The views and opinions of authors expressed herein do not necessarily state or reflect those of the United States Government or the University of California, and shall not be used for advertising or product endorsement purposes. 
PRELIMINARY RESULTS OF THE LLNL AIRBORNE

\title{
EXPERIMENTAL TEST-BED SAR SYSTEM * **
}

\author{
Mark G. Miller Carmen J. Mullenhoff Rodney D. Kiefer \\ James M. Brase Melvin G. Wieting Gary L. Berry Holger E. Jones \\ Lawrence Livermore National Laboratory \\ Livermore, CA, USA
}

\begin{abstract}
The Imaging and Detection Program (IDP) within Laser Programs at Lawrence Livermore National Laboratory (LLNL) in cooperation with the Hughes Aircraft Company has developed a versatile, high performance, airborne experimental test-bed (AETB) capability. The test-bed has been developed for a wide range of research and development experimental applications including radar and radiometry plus, with additional aircraft modifications, optical systems. The airborne test-bed capability has been developed within a Douglas EA-3B Skywarrior jet aircraft provided and flown by Hughes Aircraft Company.

The current test-bed payload consists of an X-band radar system, a navigation system, a high-speed data acquisition, and a real-time processing capability. The medium power radar system is configured to operate in a high resolution, synthetic aperture radar (SAR) mode and is highly configurable in terms of waveforms, PRF, bandwidth, etc. Antennas are mounted on a 2-axis gimbal in the belly radome of the aircraft which provides pointing and stabilization. Aircraft position and antenna attitude are derived from a dedicated navigational system and provided to the real-time SAR image processor for instant image reconstruction and analysis. This paper presents a further description of the test-bed and payload subsystems plus preliminary results of SAR imagery.
\end{abstract}

\subsection{INTRODUCTION}

The Imaging and Detection Program (IDP) within Laser Programs at Lawrence Livermore National Laboratory (LLNL) has developed an airborne test-bed capability for a wide range of sensors and experimental applications. Integrated into the airborne test-bed for SAR operation are an X-band linear frequency modulated (LFM) radar system, a high speed data acquisition and storage system, a real-time data processor system, and a dedicated navigation system. The current focus of the SAR test-bed is to support the joint US-UK Radar Ocean Imaging (ROI) Program, however other experimental operations are in development for several US military programs.

The SAR test-bed has flown a number of engineering test flights and scientific experiments over both land and ocean surfaces. The early flights have served to help characterize the performance as well as work out operational issues with the various subsystems. The test-bed has proven to be an ideal platform for ocean imaging because of the wide envelope of flight operations and endurance available. In the following sections, fundamental capabilities of the AETB will be further described and preliminary results presented.

* Presented at the IEEE 1996 National Radar Conference, Ann Arbor, Michigan, 13-16 May 1996

** Work performed under the auspices of the U.S. Department of Energy by the Lawrence Livermore National Laboratory under contract No. W-7405-ENG-48 


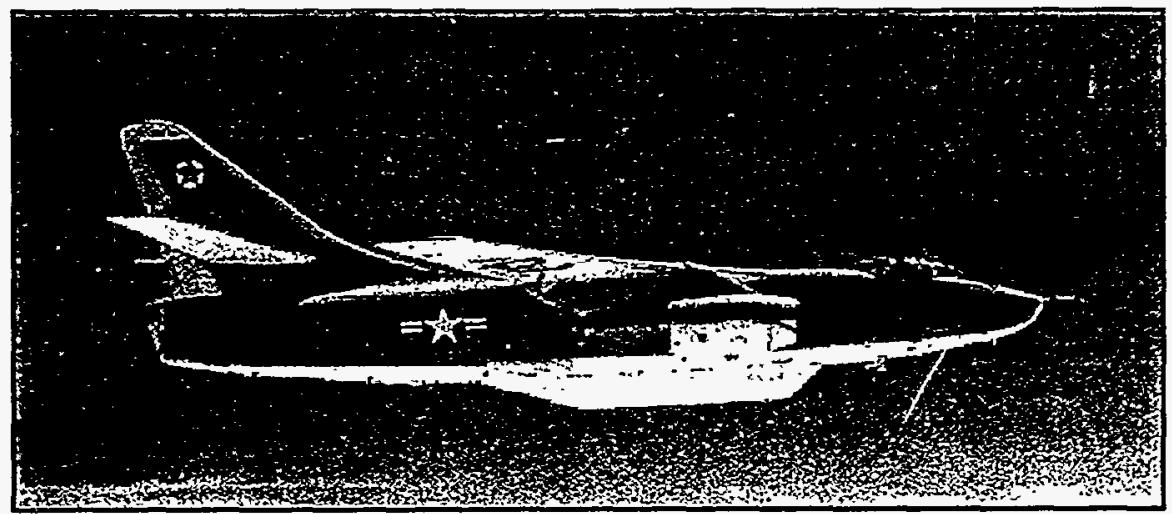

Figure 1. Navy EA-3B Jet Aircraft.

\subsection{AIRBORNE SAR TEST-BED CAPABILITIES}

The EA-3B aircraft shown in Figure 1, was selected as the test-bed platform because of its versatile performance, amount of configurable work space, and cost effectiveness to operate. The versatile airborne platform allows imaging at a variety of speeds and altitudes, while state of the art computer systems allow real-time data processing and analysis. The key subsystems have been designed as separate units so as to allow easy reconfiguration for multiple experimental operations. Minimal resources are thus required for new experimental payloads while state of the art functionality is maintained by the non-dedicated, generic subsystems.

\subsection{AIRCRAFT CONFIGURATION AND OPERATIONS}

The airborne test-bed offers a laboratory environment for the SAR and future experimental systems. The EA3B aircraft test-bed has 660 cubic feet of pressurized fuselage space for experimental hardware and multiple operation/control stations. The present test-bed configuration includes: a long narrow belly radome; multiple equipment racks; four experiment operation/control stations; and conditioned, distributed electrical power of several types.

The aircraft can cruise at airspeeds from 180 to 480 KIAS with an endurance of up to 5.7 hours giving it a range of over $2,400 \mathrm{~nm}$. It can operate at altitudes from 500 to 48,000 feet providing a potentially wide range of imaging incidence angles, and has a payload capability of between 2,000 to 8,000 lbs depending on fuel load.

\subsection{RADAR}

An instrumentation quality, fully coherent, radar system is one of the primary instruments available on the test-bed. It has the capability to operate in the S, C, X, and Ku frequency bands, although it is initially configured to operate in X-band $(9.25-9.45 \mathrm{GHz})$ with horizontal antenna polarization. Available waveforms include standard LFM up to a $125 \mathrm{MHz}$ bandwidth, stepped frequency, and stepped LFM up to a $500 \mathrm{MHz}$ bandwidth for high range resolution imaging as fine as 0.3 meters. The peak power available is $6 \mathrm{~kW}$ with a $2 \%$ duty cycle providing the system with up to $120 \mathrm{~W}$ of average power. The system incorporates inphase and quadrature demodulation which allows for separate I and $Q$ video data channels. Because a primary objective of the system is ocean surface imaging at low grazing angles, a low noise equivalent $(\mathrm{NE}) \sigma_{0}$ is required. Preliminary measurements indicate that the system can achieve $-45 \mathrm{~dB} \mathrm{NE}_{0}$. In Table 1 is a summary of the radar characteristics. The horizontally polarized antenna provides a beamwidth of $1.8^{\circ}$ in azimuth, and $8.0^{\circ}$ in elevation, and a azimuth resolution as fine as 0.61 meters. 
Table 1. Table of Radar Characteristics

\begin{tabular}{|l|l|}
\hline Frequency & X-band $(9.25-9.45 \mathrm{GHz})$ \\
\hline Polarization & $\mathrm{HH}$ \\
\hline Antenna Beamwidth & $1.8^{\circ}(\mathrm{H})$, and $8.0^{\circ}(\mathrm{V})$ \\
\hline System Modulation & $\mathrm{LFM}$, stepped frequency, stepped LFM \\
\hline LFM Bandwidth & $125 \mathrm{MHz}(500 \mathrm{MHz}$ stepped mode) \\
\hline PRF & $100 \mathrm{~Hz}-500 \mathrm{kHz}$ (selectable) \\
\hline Power & $6 \mathrm{~kW}$ peak, $\%$ duty cycle, 120 W average \\
\hline
\end{tabular}

\subsection{NAVIGATION / STABILIZATION}

A strapdown GPS aided INS system provides high resolution position and attitude data for the aircraft and more importantly for the radar antenna. The position data is provided to the pilot in a map-like display, enabling detailed flight profiles to be accurately followed. With the use of additional instruments, lateral and vertical deviations can be limited to \pm 20 meters during straight and level flight profiles.

An inertial measurement unit (IMU) located on the radar antenna provides the highly accurate antenna pointing information required for high resolution SAR reconstruction. The antenna attitude information is also used in a closed loop control system to stabilize the antenna to within $0.05^{\circ}$ in both azimuth and elevation. All navigation and attitude data is recorded and available to the computer systems at a $100 \mathrm{~Hz}$ update rate.

\subsection{ONBOARD DATA PROCESSING AND ACQUISITION}

A Mercury i860/Sparc based computer system provides the ability to perform real-time SAR image formation and system control. A high-speed analog to digital interface provides dual channel 8-bit, $200 \mathrm{MHz}$ A/D converters and memory buffering for burst rates of up to $200 \mathrm{MBytes} / \mathrm{s} / \mathrm{ch} a n n e l$ and sustained rates of up to $30 \mathrm{MBytes} / \mathrm{s} / \mathrm{channel}$. The current Radar Data Processor (RDP) system with 13 Mercury 860 processors provides the data acquisition, real-time SAR processing, and recording interface. In this configuration, the real-time SAR processor can process 1024 range cells with a 2048 cell aperture width at a sustained $500 \mathrm{~Hz}$ PRF. The VME based Sparc 10 system provides system status and control as well as display and analysis of the SAR imagery.

A high speed digital tape recorder is the primary means of recording data on the test-bed. The recorder can store up to $48 \mathrm{GBytes}$ on a cartridge tape at a rate which can vary from 0 to $30 \mathrm{MBytes} / \mathrm{s}$. A general purpose VME I/O card combines radar data, radar parameters, and navigation data and outputs it to the tape recorder. A disk array is used to store processed SAR data and can serve as a backup to the tape recorder.

\subsection{PRELIMINARY RESULTS}

Preliminary results of engineering tests with the SAR have been very successful. A series of engineering test flights were flown at Key West, FL. Three, 18 inch tetrahedral corner reflectors were placed in an L-shaped pattern, spaced 6 meters apart at the Key West Naval Air Station (NAS). The runways are shown in Figure 2 and a close up of the corner reflectors is shown in Figure 3. These images were acquired at a $70^{\circ}$ angle of incidence at 8500 meters with a $100 \mathrm{MHz}$ LFM, $5 \mu \mathrm{s}$ pulse at $1.0 \mathrm{kHz}$ PRF while maintaining a $160 \mathrm{~m} / \mathrm{s}$ velocity.

After taking range and azimuth slices through the SAR intensity image of the corner reflectors (Figure 3) we find that the SAR has obtained an azimuth resolution of 0.64 meters and a slant range resolution of 1.5 meters. Analysis of a single comer reflector with a known RCS in combination with receiver noise data, indicates a noise equivalent $\sigma_{\mathrm{o}}$ of approximately $-46 \mathrm{~dB}$. 


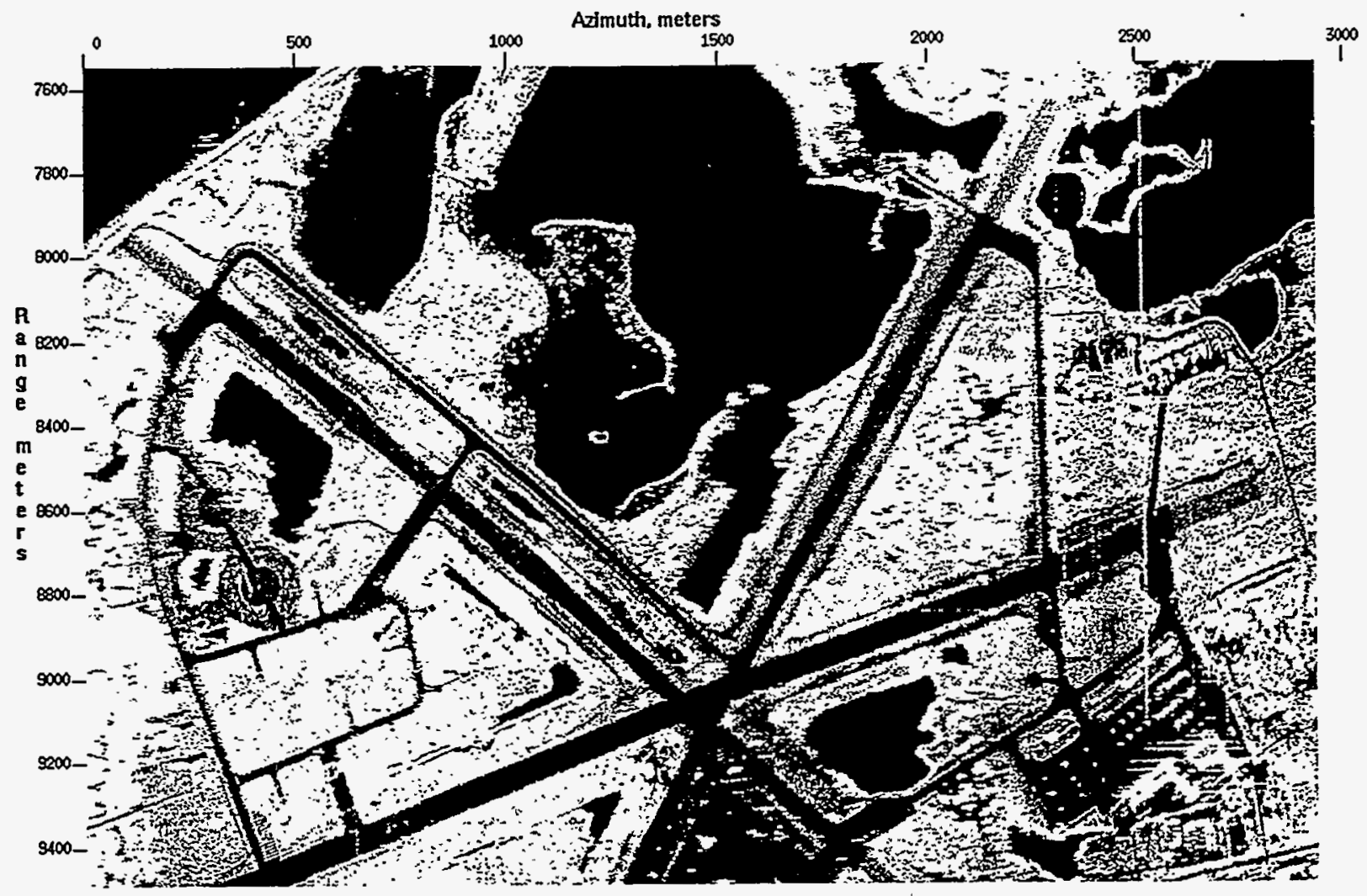

Figure 2. Key West Naval Air Station.

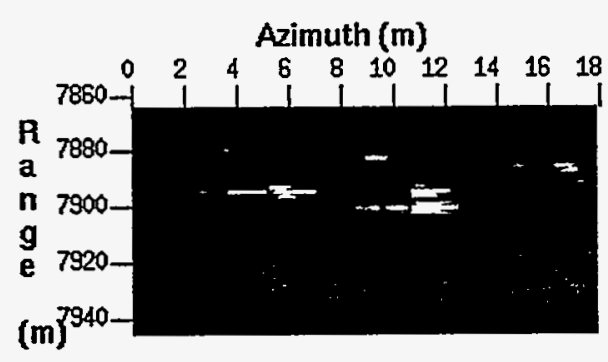

(a) Reflectors

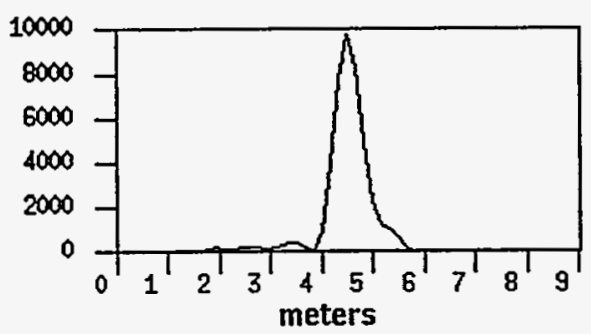

(b) Azimuth Profile

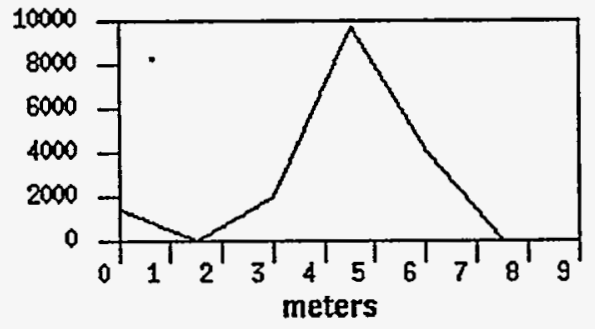

(c) Range Profile

Figure 3. Corner Reflectors At Key West Naval Air Station. 


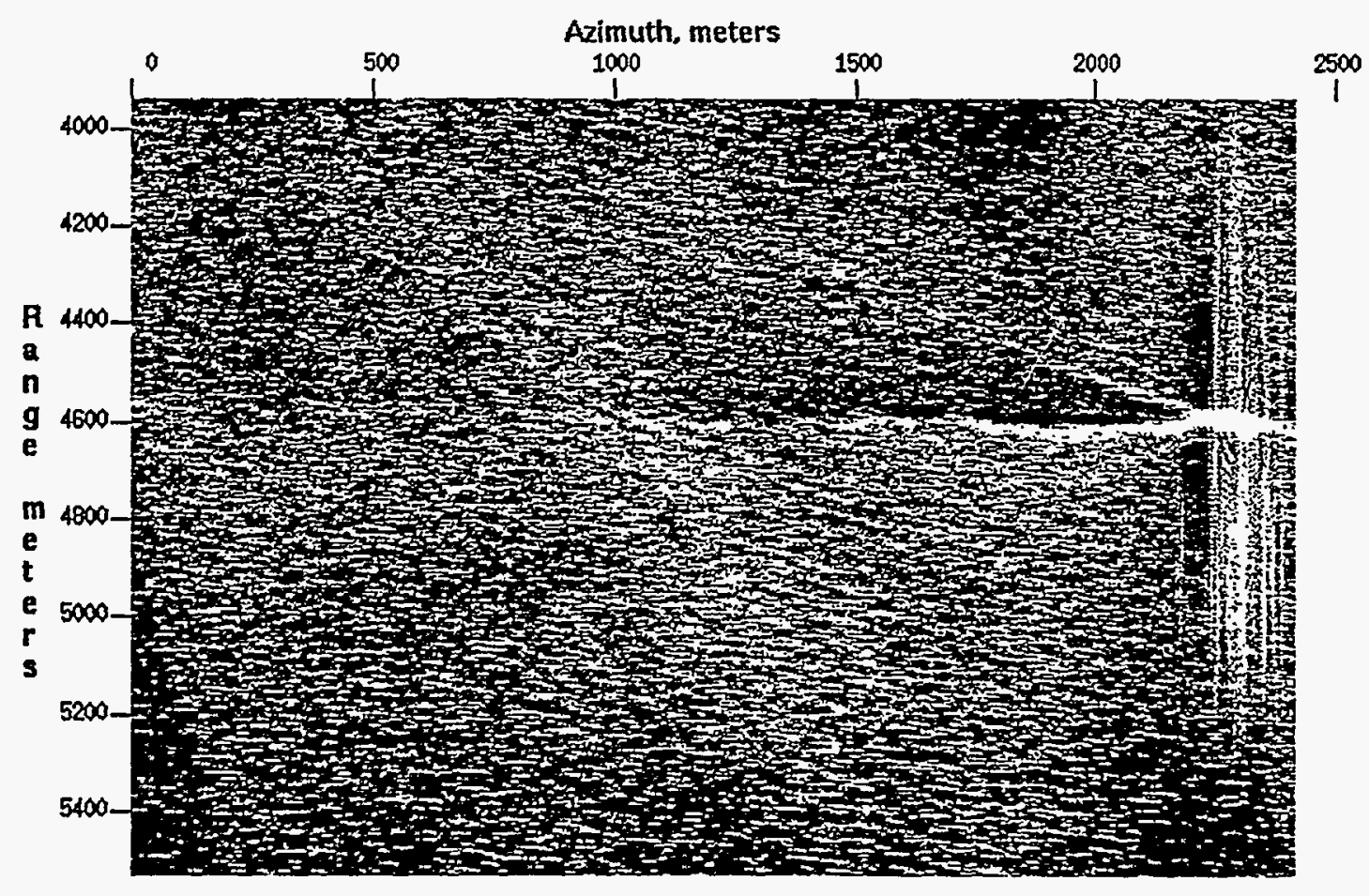

Figure 4. Ship With Wake At AUTEC Testing Range.

A SAR image of a ship wake taken at the AUTEC testing range is shown in Figure 4. This image was acquired at a $70^{\circ}$ angle of incidence at 4600 meters with a $100 \mathrm{MHz} \mathrm{LFM}, 5 \mu$ sulse at $1.0 \mathrm{kHz}$ PRF while maintaining a $135 \mathrm{~m} / \mathrm{s}$ velocity. Since we are trying to image ocean surfaces, whose backscatter is much lower than that of the "bright" ship, range sidelobes are often seen.

\subsection{CONCLUSIONS}

We have developed, in cooperation with Hughes Aircraft Company, a versatile, high performance and robust R\&D test-bed capability within the EA-3B aircraft. We have logged over 50 hours of data collection during engineering tests and mission flights with the AETB SAR payload. The $X$-band radar system has performed very well and proven to be quite reliable while the newly configured aircraft, which has not routinely flown since the Gulf War, has operated flawlessly and remarkably durable.

Collected SAR image data has been processed and verified the system resolution to be less than 1 meter in azimuth and the slant range resolution to correspond with the chirp bandwidth. Overall system parameters will continue to be evaluated in order to refine our system characterization.

Several more SAR missions will be conducted with the current SAR configuration before a series of upgrade begins. Dual antenna polarization, spot light mode operation, and a high power capability will be implemented by late 1996. 

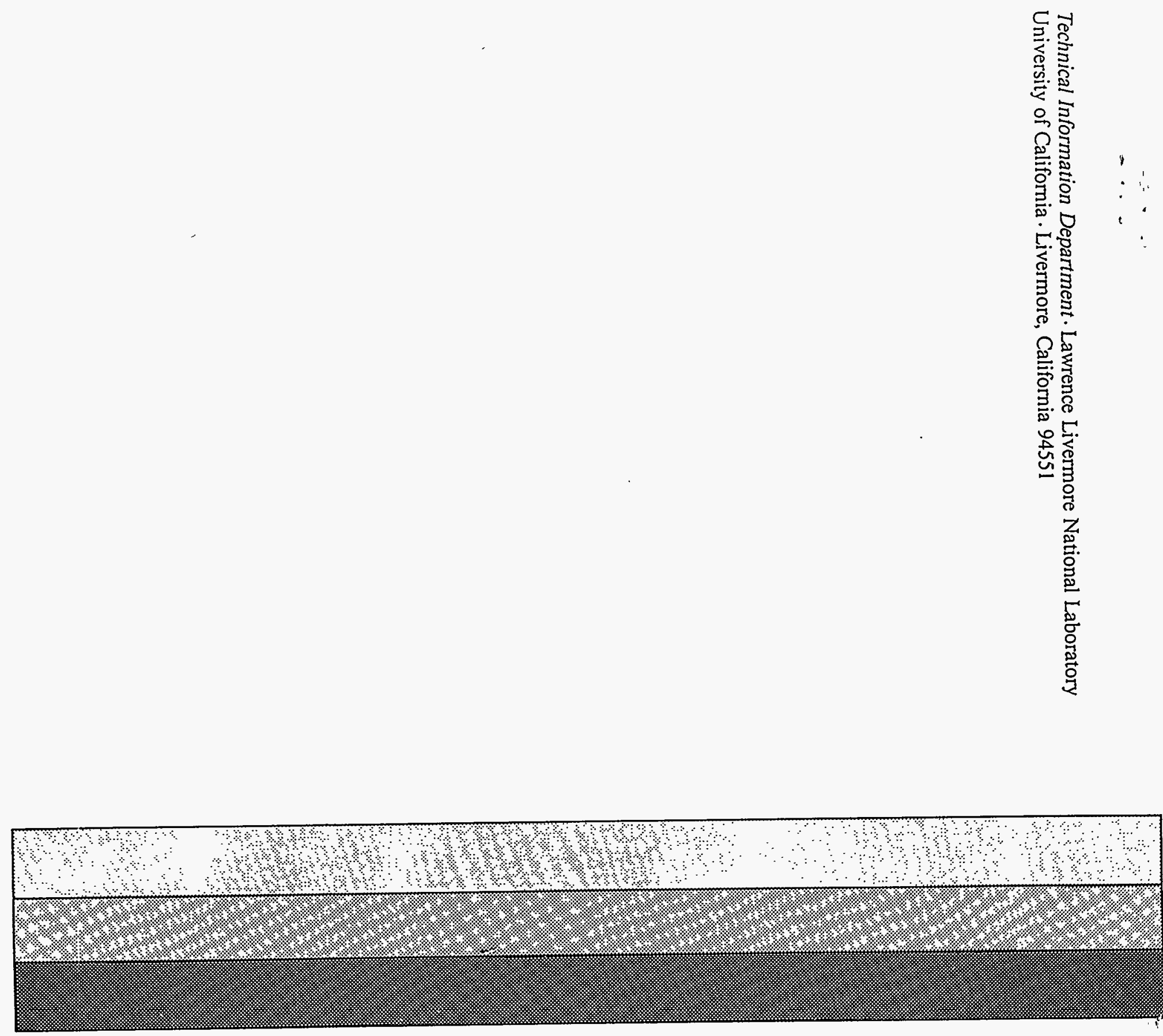